\title{
Theoretical Analysis of the Developing mode of Wushu Modernization
}

\author{
Xue $\mathrm{Yu}$ \\ Northwest University Physical Education Department \\ Xi'an Shaanxi, China 710127
}

\begin{abstract}
This paper makes an in-depth and detailed analysis for the developing mode of Wushu modernization through the general modernization theory. It also illustrates that the modernization mode should include the target realization mode and the process mode; the target developing mode of Wushu modernization is divided into the final target mode and the stage target mode; the development process mode of Wushu modernization includes the government-leading mode, the society-leading mode, as well as the government and society cooperation mode. At the same time, it points out that the government and society cooperation mode is the most ideal developing mode of Wushu modernization. It aims to provide a theoretical reference for the scientific development of Wushu modernization.
\end{abstract}

Keywords-Wushu; Modernization; Developing mode

\section{THEORY AND ClassifiCATION OF DEVELOPING MODE OF WUSHU MODERNIZATION}

Pattern is actually a methodology to solve certain problems. The mode is to sum up the method of solving certain problems to the theoretical height. From different perspectives, people often have different understanding for the same natural phenomenon or social phenomenon, which forms different theoretical modes. The so-called developing mode, namely a developing direction formed in a country, a region in a specific life scene, that is, under its own historical, economic, cultural and other background, as well as the characteristics of the system, structure, thinking, behavioral pattern and other aspects, is the selection of each country or region in the world for the political, economic system and strategy and so on in the process of implementing modernization road.

The general modernization theory holds that modernization is a state or process, and the modernization mode should include the target realization mode and the process mode. The main attribute of Wushu in modern society is sports. Its development level is largely influenced and restricted by the development level of sports modernization to a large extent. Therefore, the research on the modern developing mode of Wushu must combine the development status of sports modernization and its developing mode. In the process of sports modernization, due to different points of focus, it may emphasize target or process. Therefore, on the macro level, the mode of realizing sports modernization can be divided into two categories: target mode and process mode. [1] Wushu is a part of the China sports family. Its developing mode is consistent with the current developing mode of China sports, which is divided into target mode and process mode. However, because of the particularity of the development of Wushu modernization and its own national characteristics, it makes it different from other sports in the specific development process, and it also makes its developing mode of modernization have its own characteristics.

\section{TARGET ModE OF WUSHU MODERNIZATION DEVELOPMENT}

The target mode of Wushu modernization development is the ideal or theoretical mode of Wushu modernization development, which is put forward in order to realize the specific process mode of Wushu modernization development. Therefore, this study focuses on theoretical research on the target mode of Wushu modernization development.

The theoretical research of sports modernization holds that sports target mode is divided into absolute target mode and relative target mode. The absolute target mode is the "rational mode" of modernization, the ultimate target of the development of all human sports, and emphasizes the development state of the final stage, and the relative target mode is the "stage mode" of modernization development and realization, and is the process of a country and region realizing the preset target of a certain period in the development process, emphasizing the particular stage. According to the division of the current sports modernization target mode, combined with the development reality of Wushu modernization and its particularity, the target mode of Wushu modernization development can be divided into the final target mode and the stage target mode in the macro theory.

\section{A. Ultimate Target Mode}

The ultimate target of Wushu modernization development is a theoretical hypothesis or speculation. It is the ultimate description of the process of Wushu modernization and the ultimate target of the sports development of all human being. The description of the ultimate target mode of Wushu depends on the level and state of the modernization development of human society, that is, it can be realized only when material, energy and information and cheerful nourishment for the mind can fully satisfy the "ideal desire" of human beings [2], so it is difficult to describe it specifically. The target mode of sports modernization is to determine whether sports development can achieve modernization through comparing the target set out with the development status. As a sport, the ultimate target 
mode of Wushu is the rational target mode of Wushu modernization development. This target is a rational state, the highest level of Wushu modernization development, is also ultimate target of Wushu modernization development.

\section{B. Stage Target Mode}

Wushu modernization is a relative and dynamic concept of development. It has realized the modernization target of a certain stage or a certain period and the modernization target of the next stage. With the continuous change of its own development process, it gradually develops toward higher modernization target finally, and the formulation of the specific stage target is mainly based on the characteristics of previous Wushu modernization process and the current level of development. As stated in the Second Modernization Theory among China's modernization theories, the development of modernization is divided into "The First Modernization" and "The Second Modernization". The stage target mode of Wushu modernization development is relative to the final target mode of Wushu, all of which are stated layer by layer in theory, aiming at a comprehensive understanding of the law of development and its development trend in the process of Wushu modernization, thus providing theoretical reference for the formulation and implementation of the specific mode of Wushu modernization development.

\section{Process Mode of Wushu Modernization DEVELOPMENT}

Process mode refers to the ways, methods and approaches with relatively stable structure adopted in the process of realizing modernization. The state regulates the overall development of society from a macro perspective, and puts forward different coping strategies in different periods to meet various social needs. Therefore, in the course of sports development, from the perspective of the sports management system, the different sports modernization developing mode is formed with the state or the society (individual and group) as the main body [1].

Any developing mode has advantages and disadvantages. Nowadays, there are three developing modes of sports in the world, mainly including government-leading mode, societyleading mode and government and society cooperation mode. The so-called economic system determines the superstructure, what kind of sports developing mode is adopted by a state depends on the economic system of the state to a large extent. Looking at the current development pattern of the world economic system, there are mainly planned economic system, market economic system and mixed economic system. The law of development shows that the sports developing mode of the country carrying out the planned economic system is generally government-leading type, and the sports developing mode of the state carrying out the market economic system generally adopts the social-leading mode; the government and society cooperation mode is mainly adopted for the sports development of the state carrying out the mixed economic system. In a sense, under different economic systems or economic systems to be adopted, the three developing modes can be transformed into each other under certain conditions. According to the basic national conditions and sports system of our country and the actual situation of the development of Wushu, the government and society cooperation mode is the ideal developing mode of Wushu modernization.

\section{A. Government-leading Mode}

The government-leading mode refers to the developing mode of sports modernization with absolute management power in which the government implements the centralized and unified monitoring and management of the national sports undertakings and has absolute management authority. At present, most countries in the world adopting such mode mainly include Japan, Canada, etc.

The government plays a leading role in the formulation and implementation of sports policies, the allocation of sports resources and the sports management, which can centrally reflect the will of the state. The government can implement the direct macroeconomic regulation for the sports development through administrative power, which is conducive to the implementation of the government's sports policy and the realization of the target of sports modernization. In addition, the government-leading mode is conducive to the reasonable allocation of resources and gives full play to the role of sports resources. However, it has limitations in management and cannot reach every aspect of a matter, but master the important things other than inconsequent things, adverse to the participation and support of the society in sports.

\section{B. Society-leading Mode}

Society-leading mode refers to the developing mode of social sports organizations playing a leading role in national sports affairs. The country adopting the sports developing mode has a high degree of modernization, the social legal system is more perfect, the social participation and support abilities in sports are stronger, the sports organization is more sound and the most typical example is the United States.

For the country adopting this mode, its social sports organization plays a leading role in the formulation and implementation of national sports policies, and it also plays a leading role in the allocation of sports resources and other aspects. The government is not involved in sports affairs, and the administrative power generally does not intervene in sports affairs, thus fully guaranteeing the autonomous position of sports. Secondly, the country adopting society-leading mode has strong independence and autonomy in sports management. Because of the sound sports organization and system, it can fully undertake the establishment and implementation of system of national sports policy, the allocation of sports resources and sports management work. Thirdly, in the management operation mode, this developing mode can give full play to the enthusiasm and creativity of the social sports organization, meet the need of sports development by relying on the market means, ensure the autonomy of sports, and carry out the macro management and regulation mainly through legal and economic means, which has great flexibility. 


\section{Government and Society Cooperation Mode}

The basic feature of the government and society cooperation mode is that the government and the society jointly manage sports affairs. The most typical countries adopting this mode are France and Britain. The mode is that the government and the society jointly manage sports affairs, so as to continuously promote the modernization of sports. In this mode, the government has made an impact on the national sports cause by formulating sports policies, providing funds, etc. Therefore, the government's macroeconomic regulation of sports cause can reflect the will and interests of the government to a certain extent, and help the development of sports modernization. In addition, the implementation of sports policy and other affairs is assisted by the social sports organization to complete, and the sports organization is closely connected with the government and gives play to the function of the government's sports management efficiently and can make full use of social resources and administrative power to improve the enthusiasm of the society to participate in sports.

\section{CONCLUSIONS AND SUGGESTIONS}

According to the basic national conditions and sports system in China, combined with the actual needs of the development of sports in China, in view of the realistic condition of the current development of Wushu, the government and society cooperation mode is the ideal developing mode of Wushu modernization. In a sense, although the economic systems are different, the three developing modes can be transformed into each other under certain conditions. This also makes the government and society cooperation mode more flexible, and the scope of application is more extensive, thus becoming the preferred developing mode of Wushu modernization.

Chinese Wushu is a sport, but also a culture with strong national characteristics. As the classic representative of Chinese traditional sports, it is more needed to efficiently play the government's sports management function and make full use of social resources to improve the enthusiasm of the society to participate in sports in the process of modernization development, so that the advantages of the government and society cooperation mode can be maximized and Chinese Wushu, such human intangible cultural heritage, can be better inherited and developed.

\section{REFERENCES}

[1] Yu Daoming, Theoretical Analysis of sports modernization process mode [J]. Journal of Chengdu Sport Institute, 2011 (10).

[2] Research Group on Sustainable Development Strategy, Chinese Academy of Sciences. Strategic Conception of China's Modernization Process [M]. Beijing: Science Press, 2002.

[3] Xue Yu. Modernization Development and Evaluation of Wushu [D]. Doctoral Dissertation of Beijing Sport University, 2013. 